\title{
Parental monitoring and adolescent health risk behaviors: A comparative analysis of nine Southeast Asian countries
}

Thang Vo ( $\nabla$ thangvt@ueh.edu.vn )

Health and Agricultural Policy Research Institute, University of Economics Ho Chi Minh City

Research article

Keywords: Parental monitoring, adolescents, risky behavior, Southeast Asia

Posted Date: April 30th, 2020

DOI: https://doi.org/10.21203/rs.3.rs-23553/v1

License: (c) (1) This work is licensed under a Creative Commons Attribution 4.0 International License.

Read Full License 


\title{
Parental monitoring and adolescent health risk behaviors: A comparative analysis of nine Southeast Asian countries
}

\author{
Thang $\mathrm{T} \mathrm{Vo*}$
}

\author{
Correspondence: \\ thangvt@ueh.edu.vn \\ Health and Agricultural Policy \\ Research Institute, University of \\ Economics Ho Chi Minh City, 279 \\ Nguyen Tri Phuong, District 10, \\ Ho Chi Minh City, Vietnam. \\ Full list of author information is \\ available at the end of the article \\ *Sole contributor
}

\begin{abstract}
Background: Strong parental monitoring is thought to protect adolescents from engaging in health risk behaviors. However, differing levels of economic development and regulatory systems suggest that findings from Western countries may not generalize to Southeast Asia. This study analyzed the relationship between parental monitoring and health risk behaviors among adolescents in nine Southeast Asian countries.
\end{abstract}

Methods: Cross-sectional data for 52,803 adolescents (aged 11-18 years; $51.4 \%$ female) were obtained from the World Health Organization's Global School-Based Student Health Survey. Data collected between 2007 and 2015 was available for Indonesia, Myanmar, Thailand, The Philippines, Malaysia, Vietnam, Brunei, Timor-Leste, and Laos. Univariate and multivariate logistic regression analyses were conducted to assess the relationships between parental monitoring, sexual risk behaviors, and substance use. Age, gender, country differences in sexual risk behaviors, and substance use were also examined.

Results: The results revealed that adolescents who reported regular parental monitoring had a lower probability of engaging in sexual risk behaviors and substance use. Using alcohol, prohibited substances, and tobacco was significantly associated with engaging in sexual risk behaviors. Males and older participants were more likely than females and younger participants to report all forms of health risk behavior. Significant differences existed in risk behavior between countries, with participants in Timor-Leste the most likely to engage in most forms of health risk behavior.

Conclusion: We considered the results in the context of the economic and regulatory environments in each country. In developing countries, particularly those with relatively strong economic growth and relaxed drug and alcohol regulations, parental monitoring, and other factors such as culture, education, and the health system play a crucial role in protecting adolescents from risky behaviors.

Keywords: Parental monitoring; adolescents; risky behavior; Southeast Asia 


\section{Background}

Adolescents are more likely to be at risk of engaging in risky behaviors than individuals in any other developmental stage [1]. Teenagers develop risky behaviors during adolescence due to both individual and environmental factors [2, 3, 4]. Adolescents do not have much experience in life, and together with the biological and psychological changes they experience, this increases the potential for impulsive sexual behaviors $[5,6,7]$ and the use of substances [8], which can lead to accidental self-harm $[9,10]$. At the same time, the influence of peers and even sexual partners makes it even more difficult for teenagers to control their behavior [11, 12, 13]. Factors such as community $[14,15]$, religious beliefs $[16,17,18]$, and also the media $[19,20]$ can influence behavior during adolescence. Notably, the literature shows that the family has a crucial role in providing timely intervention and correction to adolescents' risky behaviors, along with appropriate direction [21, 22, 23, 24]. Parental monitoring is an essential factor determining the safety of the health risks of adolescents $[25,26,27,28]$.

Parental monitoring is defined as "a set of correlated parenting behaviors involving attention to and tracking of the children's whereabouts, activities, and adaptation [27].” Although another study suggested that the concept of parental monitoring would be more appropriately termed "parental understanding [26]," later studies do not put too much emphasis on the terminology used and use definitions consistent with the measurement criteria $[29,30,25,31,32]$.

The social development model argues that adolescents' relationships with school and family, which are influenced by parental behaviors, play a critical role in children's social development before and during adolescence, including use of illicit substances and unsafe sex behaviors [33]. When teenagers become aware of parental monitoring, they may modify their own behaviors, such as who they spend their free time with. A lack of parental monitoring is associated with increased health risk behaviors, including recent use of marijuana and alcohol, violent acts, unsafe sexual practices such as not using a condom and having multiple sexual partners, and a positive test for sexually transmitted diseases [25]. Several subsequent studies 
have shown similar results [23, 34, 35, 36, 37].

While parental monitoring occurs at the family level, macro-level factors, such as national policies and the failure of the health benefits system, also contribute to adolescent health risk behaviors [38, 39, 40]. Such factors are particularly crucial in developing countries, where the quality of children's health and development is closely linked to poverty, as well as ineffective intervention policies [41, 42, 43]. Among developing regions, Southeast Asian countries need to direct more effort into protect the young generation in the process of economic development [44].

The issue of health risk behaviors among adolescents in Southeast Asian countries has received some attention (e.g., [45]; [46]; [47]). For example, in Thailand, one study found a link between parental monitoring, belief in Buddhism, and drug use and sexual risk taking in teenagers aged 13 and 14 years old [48]. In Vietnam, research showed that strong parental attention protects children from health risk behaviors, especially those living in urban areas [49]. Also in Vietnam, another study showed a positive correlation between alcohol use and sexual risk behavior among young people aged 16 to 24 years [50]. Other prominent studies have been conducted in Laos and Cambodia [51, 52], Malaysia and the Philippines [53, 54, 55] and Timor-Leste [56, 57].

Previous studies of health risk behaviors among adolescents in Southeast Asia have reviewed the health risk behaviors independently. Researchers havefocused on adolescent risk behaviors in single countries, often at the provincial or regional level. Few studies have considered the role of parental monitoring in adolescent health risk behavior in Southeast Asia, and those that have employed various methods, making it difficult to compare the results across countries. Hence, this study becomes the first attempt to analyze the relationship between parental monitoring and health risk behaviors among adolescents across multiple countries in the Southeast Asian region. This study is also the first to conduct a cross-country analysis of the correlation between sexual risk behavior and substance use among adolescents in the Southeast Asian region.

\section{Method}




\section{Participants and data collection}

The Global School-Based Student Health Survey (GSHS) was developed by the World Health Organization (WHO) and the Centers for Disease Control and Prevention in collaboration with UNICEF, UNESCO, and UNAIDS. The GSHS uses a standardized scientific sample selection process; common school-based methodology; and core questionnaire modules, core-expanded questions, and country-specific questions that are combined to form a self-administered questionnaire that can be administered during one regular class period. (Details are provided in the CDC's website). This study used cross-sectional data collected between 2007 and 2015 from nine Southeast Asian countries: Indonesia (2007), Myanmar (2007), Thailand (2008), the Philippines (2011), Malaysia (2012), Vietnam (2013), Brunei (2015), Timor-Leste (2015) and Laos (2015).

Among the nine countries surveyed in Southeast Asia, 52,803 adolescents (51.4\% female) participated in the interviews. Participants were school attendees aged between 11 and 18 years old, the majority of which were teenagers aged 13 to 18: 18.38\% aged 13 years, $22.72 \%$ aged 14 years, $22.14 \%$ aged 15 years, and $33.44 \%$ aged 16 to 18 years. There is not much difference between countries in age and gender.

\section{Measurement}

The GSHS questionnaire contains 10 core self-administered modules that measure the leading causes of death and disability among young people and adults, globally. The modules cover a wide range of risk factors, as well as physical and mental health. For the purpose of the current study, we selected relevant items from the modules for alcohol use, drug use, and protective factors.

Independent variable: parental monitoring

Toassess parental monitoring, participants were asked two questions about whether or not their parents know how they spend their spare time and how much their 
parents understand their concerns and problems. For the former, the question was "During the past 30 days, how often did your parents or guardians really know what you were doing with your free time?" For the latter, the question was "During the past 30 days, how often did your parents or guardians understand your problems and worries?" Responses to both questions ranged from $1=$ "Never" to $5=$ "Always." For the purpose of the current study, responses to both questions were combined into a single binary variable. Regular parental monitoring (value $=1$ ) included participants who responded "Almost all the time" or "Always" to both questions. Lack of parental monitoring (value $=0$ ) included all remaining participants.

\section{Dependent variables}

A single question was used to assess whether participants had ever had sexual intercourse: "Have you ever had sex?" Responses were coded as $\mathrm{o}=$ "No" and $1=$ "Yes."

Condom use and number of sexual partners were assessed as indicators of sexual risk behavior. Condom use was assessed with the question "During the most recent sexual intercourse, did you or your partner use a condom?" The response options were "Yes," "No," and "I have never had sex." For the purpose of the current study, responses were divided into two groups: $\mathrm{o}=$ "Yes" or 1 = "I have never had sexual intercourse" or "No." Number of sexual partners was assessed with the question "During your life, with how many people have you had sexual intercourse?" Response options were "I have never had sexual intercourse" followed by the numbers 1 to 6 . For the purpose of the current study, responses were divided into two categories: $\mathrm{O}=$ "o to 1 sexual partner" and $1=$ " 2 or more sexual partners." The latter group was considered to be at higher risk of unsafe sex behaviors [58]. Alcohol or alcoholic beverage use was measured by asking how many days a participant had drunk at least one bottle of alcoholic beverage in the last 30 days. Participants were divided into two groups: the first group consisted of children who consumed alcohol or other alcoholic beverages for more than one day and were assigned a value of one; the second group, that is, the non-user group, was assigned a value of zero. 
Use of prohibited substances was measured as the number of times participants had ever used marijuana or illicit stimulants. Marijuana use was determined with the question "During your life, how many times have you used marijuana?” Illicit stimulant use was determined with the question "During your life, how many times have you used amphetamines or methamphetamines?” Response options to both questions ranged from $1=$ "o times" to $5=$ " 20 or more times." For the purpose of the current study, responses to both questions were combined into a single binary variable. Never used prohibited substances $($ value $=0$ ) included participants who responded "Never" to both questions. Use of prohibited substances (value $=1$ ) included all remaining participants $[59,60,61,62]$.

Tobacco use was measured as the number of days that participants had smoked tobacco in the last 30 days: "During the past 30 days, on how many days did you smoke cigarettes?" Response options ranged from 1 = "o days" to 7 = "All 30 days." For the purpose of the current study, responses were recoded into two categories: 0 $=$ "o days" and $1=$ " 1 or more days" $[63,64,65]$.

\section{Control variables}

The two control variables used were gender and age at the time of the survey. The gender variable was a binary variable: $0=$ males and $1=$ females. Prior to 2008, the GSHS participants were aged 11 to 16 years old. From 2008, the age range was extended and included participants aged 11 to 18 years old. For the purpose of the current study, age was categorized into six categories: $1=11$ years old, $2=12$ years old, $3=13$ years old, $4=14$ years old, $5=15$ years old, and $6=16$ to 18 years old.

\section{Country}

To account for the differences between countries, eight dummy variables were created to correspond to the nine countries. Each dummy variable was coded o and 1, with Vietnam used as the base category (value $=0$ ). 


\section{Research models}

152

153

154

155

156

157

158

159

160

161

162

163

164

165

166

167

168

169

170

171

172

173

174

175

The research was designed as a cross-sectional study that aimed to test two models.

The first model was designed to study the relationship between parental monitoring and health risk behaviors among adolescents, including unsafe sex and the use of substances. The second model looked at the association between substance use and unsafe sex behaviors.

Call $Y_{i}$ the variable that indicates the $i^{\text {th }}$ health risk behavior. $Y_{i}$ equals 1 or $\mathrm{o}$, where 1 indicates the presence of a health risk behavior, and o indicates the absence. Call $\pi=p\left(Y_{i}=1\right)$ the probability that $Y_{i}=1$. Thus, the probability that an individual did not report a given health risk behavior $\left(Y_{i}=0\right)$ is defined as $p\left(Y_{i}=0\right)=1-p\left(Y_{i}=1\right)=1-\pi$. The value of $\pi$ varies from o to 1 . When $\pi$ $=1$, the health risk behavior is certainly present, and when $\pi=0$, the health risk behaviors is certainly absent.

The odds ratio (OR) is defined as the probability that an event occurred divided by the probability that it did not occur. The OR has a value between 0 and $+\infty$. If Odds $=0$, the event never occurred. If $\operatorname{Odd} s=1$, the probability of it occurring or not occurring is the same. When the odds increase from o to almost 1 , the probability of the event occurring is increasing, but still less than the probability of no occurrence. When the odds increase from 1 to $+\infty$, the probability of the event occurring is greater than the probability of no occurrence [66, 67].

For adolescent health risk behaviors, the OR $\left(Y_{i}=1\right)$ was defined as follows:

$$
O D D\left(Y_{i}=1\right)=\frac{p\left(Y_{i}=1\right)}{p\left(Y_{i} \neq 1\right)}=\frac{p\left(Y_{i}=1\right)}{p\left(Y_{i}=0\right)}=\frac{\pi}{1-\pi}
$$


Model (1) examined the relationship between parental monitoring and health risk behaviors among adolescents as follows:

$\operatorname{ODDS}\left(Y_{i}=1\right)=\beta_{1}+\beta_{2}$ Age $+\beta_{3}$ Gender $+\beta_{4}$ Parent $+\beta_{x}$ Country $+\varepsilon$

180

181

182

183

184

185

186

187

188

189

190

191

192

193

194

195

196

197

198

199

200

201

202

203

204

The coefficient $\beta_{k}(k=2: 4)$ in Model (1) represents the degree of change in the probability of $Y_{i}$ (ith health risk behavior). Therefore, if $\beta_{k}<1$, the corresponding independent variable reduced the $\operatorname{ODDS}\left(Y_{i}=1\right)$, or reduced the probability that the given health risk behavior occurred (i.e., the two variables were negatively related). While $\beta_{k}>1$ indicates a positive relationship, $\beta_{k}=1$ means that the two variables do not have any association $[66,67]$. The coefficient $\beta_{x}(x=5: 13)$ corresponds to the dummy variable of Country, representing the difference in health risk behaviors $\left(Y_{i}\right)$ between the Country and Vietnam.

Model (2) examined the relationship between substance use and sexual risk behaviors and was defined as follows:

$$
\begin{aligned}
\operatorname{ODDS}\left(Y_{j}=1\right)= & \beta_{1}+\beta_{2} \text { Age }+\beta_{3} \text { Gender }+\beta_{4} \text { Alco } \\
& +\beta_{5} \text { Subs }+\beta_{6} \text { Smoke }+\beta_{x} \text { Country }+\varepsilon(2)
\end{aligned}
$$

Where $Y_{j}$ is the variable that indicates whether or not the $j^{\text {th }}$ risky sexual behavior occurred. $j^{\text {th }}$ has the values of 1 and $o$, where 1 indicates that the $j^{\text {th }}$ risky sexual behavior occurred, and o indicates the opposite. The coefficient $\beta_{k}(k=2: 6)$ in model 2 shows the degree of change in the OR of $Y_{j}\left(j^{\text {th }}\right.$ risky sexual behavior) due to the influence of the corresponding independent variable with the coefficient $\beta k$.

\section{Data analysis}

Data were analyzed using Stata 16 in sequential steps. Data from each country was processed and combined into a unified data set, incomplete or missing data were excluded. Next, we examined the difference in prevalence of each health risk behavior between those with regular parental monitoring compared to those lacking parental monitoring. Following this, a series of univariate and multivariate logistic regression analyses were performed to test the impact of parental monitoring 
(independent variable) on each of the health risk behaviors (dependent variables). With the multivariate analyses, we adjusted for differences in gender, age, and country. We also conducted logistic regressions to examine the difference in health risk behavior between the categories of gender, age, and country. The results from univariate models, which showed the correlation between the two separate variables, were used as the basis for building the multivariate models. Thus, the regression results in the multivariate model were mainly used for interpreting the empirical results $[66,25,67]$.

\section{Results}

\section{Descriptive statistics}

Table 1 and 2 present the descriptive results for age, gender, parental monitoring, substance use, and risky sexual behaviors of 52,803 adolescents in nine countries in Southeast Asia. The majority of participants reported that they did not receive regular parental monitoring (78.32\%). Experience of sexual intercourse was reported by $6.94 \%$ of the sample. Of those who had ever had sexual intercourse, the proportion of female participants who reported that they used to have sex was $40.27 \%$ compared to $59.73 \%$ of male participants. Among adolescents who had ever had sex $(n=3,662)$, the proportion who did not use condoms during the last sexual encounter was quite high (22.04\%). Use of prohibited substances was reported by $13.95 \%$ of participants, alcohol use was reported by $13.64 \%$, and tobacco smoking as reported by $11.22 \%$.

(Tables 1 and 2 near here)

\section{Parental monitoring and health risk behaviors}

Table 3 shows that participants who regularly received parental monitoring were less likely to exhibit health risk behaviors than those who lacked parental monitoring. Specifically, for the group who regularly received parental monitoring, 8.29\% reported alcohol use, compared to $15.12 \%$ of those who lacked parental monitoring. Prohibited substance use and tobacco use were reported by $10.25 \%$ and $6.99 \%$, respectively, of those with regular parental monitoring and $14.97 \%$ and $12.39 \%$, 
respectively, of those who lacked parental monitoring. Participants with regular parental monitoring also reported lower levels of risky sexual behaviors. Ever having had sex was reported by $4.45 \%$ of those with regular parental monitoring and $7.62 \%$ of those with a lack of parental monitoring. No condom used during the most recent sexual encounter was reported by $1.04 \%$ of those with regular parental monitoring and $2.24 \%$ of those lacking parental monitoring.

\section{(Table 3 near here)}

Table 3 also presents the results from the univariate and multivariate logistic regression models, in which the independent variable was parental monitoring. The results for the univariate analyses show that regular parental monitoring was associated with reduced health risk behaviors among adolescents. Specifically, regular parental monitoring significantly reduced the likelihood of using prohibited substances $(O R=0.64)$, tobacco smoking $(O R=0.53)$, and alcohol use $(O R=0.50)$. Regular parental monitoring also reduced the likelihood of ever having had sex $(O R=0.56)$, not using a condom during the last sexual encounter $(O R=0.45)$, and having two or more sexual relationships.

Next, we compared the prevalence of health risk behaviors between males and females (Table 4). Results from the multivariate model showed that, compared to males, females were significantly less likely to report ever having had sex $(O R=0.62)$, not using a condom during the last sexual encounter $(O R=0.57)$, and having two or more sexual partners $(O R=0.36)$. Females were also less likely to have use prohibited substances $(O R=0.46)$, alcohol $(O R=0.51)$, and tobacco $(O R=0.12)$. In the univariate analyses of prohibited substances, males and females reported almost the same prevalence of prohibited substance use (11.19\% vs. $11.72 \%$, respectively; $O R=0.93)$. In the multivariate model, however, females were almost 50\% less likely to use prohibited substances than males $(O R=0.046)$.

(Table 4 near here)

Table 5 shows the association between age and health risk behaviors. Participants aged 12 had a significantly lower probability of ever having had sex $(O R=0.55)$. No other category of age was significantly associated with ever having had sex. 
Older age groups had a higher rate of condom use $(O R=1.39)$. There was a significant association between age and substance use, with younger participants being less likely to use alcohol $(O R=1.25)$ and smoke tobacco $(O R=1.33)$. However, younger children had a higher probability of using prohibited substances $(O R=0.91)$. Participants aged $13(O R=0.40)$ and 14 years $(O R=0.41)$ had the highest likelihood of using prohibited substances.

(Table 5 near here)

\section{Association between substance use and risky sexual behaviors}

Table 6 shows the results for the multivariate analyses examining the relationships between age, gender, and substance use with risky sexual behaviors. Reported use of alcohol, prohibited substances, and tobacco smoking were all significantly associated with a higher probability of risky sexual behaviors. Participants who used prohibited substances were most at risk of sexual behaviors, particularly having two or more sexual partners $(O R=7.86)$. Participants who reported alcohol use $(O R=2.3)$ and tobacco smoking $(O R=2.11)$ were also more likely to report multiple sexual partners. Use of prohibited substances $(O R=3.10)$, tobacco smoking $(O R=1.85)$, and alcohol $(O R=1.49)$ were all associated with an increased likelihood of ever having had sex. The probability of not using a condom during the last sexual encounter was significantly higher among participants who reported smoking tobacco $(O R=2.84)$, prohibited substances $(O R=2.63)$, and alcohol use $(O R=1.95)$. Compared to males, females reported significantly fewer risky sexual behaviors: ever had sex $(O R=0.76)$ and two or more partners $(O R=0.53)$. The rate of reporting no condom use was not significantly different between males and females $(O R=0.87)$.

(Table 6 near here)

\section{Differences in health risk behaviors across countries}

Table 7 compares the prevalence of risky sexual behavior across the nine Southeast Asian countries. Each country was coded as a dummy variable with Vietnam as the reference category. Compared to Vietnam, Timor-Leste had the highest rate of ever 
having had sex $(O R=3.86)$, followed by Laos $(O R=2.27)$, Brunei $(O R=2.21)$, and Malaysia $(O R=1.41)$. Participants in Indonesia were the least likely, among all nine countries, to report ever having had sex $(O R=0.12)$. Regarding condom use, participants in Indonesia $(O R=4.74)$ and Thailand $(O R=4.61)$ were most likely to report not using a condom during the last sexual encounter, followed by Timor-Leste $(O R=3.28)$. Multiple sexual partners was reported most frequently by participants in Timor-Leste $(O R=7.02)$, followed by Thailand $(O R=6.58)$, Laos $(O R=2.02)$, and Brunei $(O R=1.76)$.

\section{(Table 7 near here)}

Table 8 compares the prevalence of substance use in each country, with Vietnam as the reference group. Only Thailand had a higher prevalence of reported alcohol use than Vietnam $(O R=1.23)$. Indonesia $(O R=0.24)$, Malaysia $(O R=0.24)$, Brunei $(O R=0.19)$ and Myanmar $(O R=0.17)$ all showed lower rates of alcohol use than Vietnam. There was no significant difference in alcohol use between Vietnam and the Philippines $(O R=0.92)$, Timor-Leste $(O R=0.91)$ and Laos $(O R=1.08)$. For prohibited substance use, the country with the highest risk was Timor-Leste $(O R=13.09)$, followed by Thailand $(O R=3.54)$, Malaysia $(O R=1.99$, Brunei $(O R=1.94)$, and Laos $(O R=1.39)$. The two countries with the lowest risk of prohibited substance use were Indonesia $(O R=0.34)$ and Myanmar $(O R=0.24)$. Vietnam had the lowest rate of tobacco smoking, and the highest rate of smoking was in Timor-Leste $(O R=7.32)$, followed by Indonesia $(O R=5.02)$, Thailand $(O R=4.24)$, the Philippines $(O R=3.78)$, Brunei $(O R=3.03)$, Malaysia $(O R=$ 2.88), and finally Myanmar $(O R=1.73)$.

(Table 8 near here)

\section{Discussion}

Few studies have considered the effect of parental monitoring on health risk behaviors during puberty and adolescence, and no studies have conducted a cross-country analysis of this relationship in the Southeast Asian region. This study aimed to address this gap. The results showed that regular parental monitoring protected adolescents from risky behaviors, including sexual and substance use risk behav- 
iors. This study also found that substance use was associated with increased risky sexual behavior. At the same time, the prevalence of adolescent health risk behavior varied between males and females, age groups, and Southeast Asian countries.

These findings are consistent with previous studies in which parental monitoring is associated with reduced health risk behaviors among adolescents [25, 26, 68, 69]. However, while Borawski et al., [63] found that parental monitoring was associated with risky behavior in a univariate model, when other parental characteristics were added to the model, parental monitoring did not show a strong correlation with health risk behaviors. They concluded that parental monitoring alone is not sufficient to protect children from dangerous behaviors. However, it should be noted that the authors only surveyed adolescents in grades 9 and 10 in the US [63]. This was a group of children at the height of puberty, when the effects of parenting may be more complex.

The positive relationship between substance use and unsafe sex found in this study was similar to previous studies [70, 59, 71, 72, 64]. However, this result was different from one study of Valera et al., [73] who found that heavy use of alcohol and drugs did not lead to an increased risk of unsafe sex and HIV. The study by Valera et al., [73] focused on young, mature men. It is possible that a greater understanding of the risks and lower impulsiveness made their behavior different from the group surveyed in the current study.

The differences in health risk behaviors between the nine countries we studied may be explained by several social vulnerability factors $[39,40]$. These factors include the level of development of the health and welfare system, economic development, culture, market characteristics of prohibited substances (e.g., production, distribution, and consumption), and the regulatory system. Based on our research results, combined with data from the World Bank and WHO on alcohol and health in Southeast Asia [74], we examined the differences between Southeast Asian countries in two aspects: (1) the economic environment, as shown by the GDP index of the countries in the period from 2000 to 2018, corresponding to the time the GSHS was conducted in that country, and (2) the regulatory environment, as shown by alcohol regulations and policies (Table 9). 
(Table 9 near here)

Among the nine countries covered by this study, the association between economic growth and adolescent health risks was unclear. Except for Brunei, which has exceptionally high per capita incomes, countries with higher per capita GDP (Thailand, Timor-Leste, Indonesia, and Malaysia) mostly had a higher prevalence of adolescent health risk behavior. Countries with lower incomes (the Philippines, Vietnam, Laos, and Myanmar) had relatively lower levels of risky behaviors. Although it is inconclusive, this suggests the possibility that economic growth can have adverse effects on adolescents.

(Figure 1 near here)

Regarding the regulatory environment, although all countries imposed special 369 (Table 9). Specifically, Timor-Leste had almost no strict legal policies to control the use of alcoholic beverages; this may have affected adolescents' behavior directly. In Thailand and Indonesia, however, there were stricter rules. The minimum age for consuming alcohol was 20 years, higher than the age of 18 in the middle-income countries. All countries had regulations on limiting the number of products sold, except Vietnam and Timor-Leste. This may explain the reason for the significantly high level of alcohol use among Vietnamese and Timor-Leste adolescents. Thus, we propose that although there were differences in country-specific regulations, in general, regulatory factors had an impact on adolescents' health risk behaviors.

Notably, although Thailand and Indonesia are both higher middle-incomecountries, participants in Thailand reported more risk behavior than those in Indonesia. This was despite the strict laws in Thailand and the relatively relaxed regulations in Indonesia. This suggests that, apart from economic and legal factors, other factors such as culture, or the education and health system, play a crucial role in the health of a nation and its adolescent population $[75,76]$.

The finding that health risk behaviors were greatest in Timor-Leste can be explained by all of the above. Although the average GDP was quite high in Southeast Asia between 2007 and 2015, Timor-Leste was a country with an outdated economic 
system with a very low total GDP. In fact, it had the lowest GDP in the region, with unstable economic growth rate and a significant gap between the rich and the poor [77, 78]. Due to regaining independence in 2002, education in this country was facing numerous challenges because people spoke many different languages. Just over half of Timor-Leste's population was literate. The percentage of school-aged children not attending school was also high, resulting in deficient access to information and education for Timor-Leste adolescents [79, 80]. This also explains the "looseness" in Timor-Leste's alcohol laws. There was almost no regulation on the use of drugs and alcohol, in general, and the government lacked interest in funding supportive programs and developing national action plans [74]. Due to the limitations of the GSHS questionnaire, this study did not include factors that may have influenced the relationship between parental monitoring and health risk behaviors, such as culture, family structure, education, or parents' income [81]. Some risk behaviors, such as certain contraception methods, were not considered due to data heterogeneity across countries. Some of the variables studied only captured information from the 30 days prior to taking the survey; therefore, risk behaviors that occurred more than 30 days earlier were omitted, which could have affected the results. Since the analysis was based on self-reported data of students, the findings cannot be generalized to youth who are not attending schools. In addition, because only cross-sectional data was used, the results should not be interpreted as causal effects.

\section{Conclusion}

There has been limited cross-country research on the relationship between parental monitoring and health risk behaviors among adolescents in Southeast Asia. We aimed to bridge this gap by examining this relationship in a large, representative sample of adolescents from nine Southeast Asian countries. Moreover, this study is the first to provide cross-country evidence for the correlations between parental monitoring, substance use, and health risk behaviors among adolescents in the region. Together with our analysis of the economic and regulatory environment in 
each country, the results suggest that economic growth may have adverse effects on adolescents' behavior, and this may be compounded when there are relaxed regulations on drug and alcohol use. Therefore, in such countries, parental monitoring may play a particularly crucial role in protecting adolescents from health risk behaviors, along with the nation's education and healthcare systems.

\section{List of abbreviations}

ASEAN:Association of South-East Asian Nations

GDP: Gross Domestic Product

GSHS: Global School-Based Student Health Survey

WHO: World Health Organization

\section{Declarations}

Ethics approval and consent to participate: Not applicable

Consent for publication: Not applicable

Availability of data and materials:

Authors can confirm that all relevant data are included in the article and/or its supplementary information files

Competing interests: The authors declare that they have no competing interests.

Funding:

This research did not receive any specific grant from funding agencies in the public, commercial, or not-for-profit sectors. 

read, and approved the final manuscript. Quoc Cuong for his excellent assistance with data. Any errors are solely mine.

\section{References}

454
1. Galvan, A., Hare, T., Voss, H., Glover, G., Casey, B.: Risk-taking and the adolescent brain: Who is at risk? Developmental science 10(2), 8-14 (2007)

2. DiClemente, R.J., Crittenden, C.P., Rose, E., Sales, J.M., Wingood, G.M., Crosby, R.A., Salazar, L.F.: Psychosocial predictors of hivassociated sexual behaviors and the efficacy of prevention interventions in adolescents at-risk for hiv infection: what works and what doesn't work? Psychosomatic Medicine 70(5), 598-605 (2008)

3. Sheeran, P., Abraham, C., Orbell, S.: Psychosocial correlates of heterosexual condom use: a meta-analysis. Psychological bulletin 125(1), 90 (1999)

4. Williams, R.L., Fortenberry, J.D.: Update on adolescent condom use. Current Opinion in Obstetrics and Gynecology 23(5), 350-354 (2011)

5. Herbenick, D., Reece, M., Schick, V., Sanders, S.A., Dodge, B., Fortenberry, J.D.: Sexual behavior in the united states: Results from a national probability sample of men and women ages 14-94. The Journal of Sexual 
Medicine 7, 255-265 (2010)

6. Scott-Sheldon, L.A.J., Johnson, B.T.: Chapter 9 - the sexual health of adolescents: When, where, and why adolescents use contraceptives. In: Bromberg, D.S., O’Donohue, W.T. (eds.) Handbook of Child and Adolescent Sexuality, pp. 221-251. Academic Press, San Diego (2013)

7. Fortenberry, J.D.: Chapter 7 - sexual development in adolescents. In: Bromberg, D.S., O’Donohue, W.T. (eds.) Handbook of Child and Adolescent Sexuality, pp. 171-192. Academic Press, San Diego (2013)

8. Donovan, J.E., Jessor, R., Costa, F.M.: Adolescent health behavior and conventionality-unconventionality: An extension of problem-behavior therapy. Health Psychology 10(1), 52 (1991)

9. Hoyle, R.H., Fejfar, M.C., Miller, J.D.: Personality and sexual risk taking: A quantitative review. Journal of personality 68(6), 1203-1231 (2000) 10. Bri`ere, F.N., Rohde, P., Seeley, J.R., Klein, D., Lewinsohn, P.M.: Adolescent suicide attempt and adult adjustment. Depression and Anxiety 32(4), 270-276 (2014)

11. Henry-Reid, L.M., O’Connor, K.G., Klein, J.D., Cooper, E., Flynn, P., Futterman, D.C.: Current pediatrician practices in identifying high-risk behaviors of adolescents. Pediatrics 125(4), 741-747 (2010)

12. Ali, M.M., Amialchuk, A., Dwyer, D.S.: Social network effects in contraceptive behavior among adolescents. Journal of Developmental \& Behavioral Pediatrics 32(8), 563-571 (2011)

13. Kenyon, D.B., Sieving, R.E., Jerstad, S.J., Pettingell, S.L., Skay, C.L.: Individual, interpersonal, and relationship factors predicting hormonal and condom use consistency among adolescent girls. Journal of Pediatric Health Care 24(4), 241-249 (2010) 14. Kerrigan, D., Witt, S., Glass, B., Chung, S.-e., Ellen, J.: Perceived neighborhood social cohesion and condom use among adolescents vulnerable to hiv/sti. AIDS and Behavior 10(6), 723-729 (2006) 15. Ford, J.L., Browning, C.R.: Neighborhood social disorganization and the acquisition of trichomoniasis among young adults in the united states. 
American journal of public health 101(9), 1696-1703 (2011)

16. Rostosky, S.S., Wilcox, B.L., Wright, M.L.C., Randall, B.A.: The impact of religiosity on adolescent sexual behavior: A review of the evidence. Journal of Adolescent Research 19(6), 677-697 (2004)

17. Sinha, J.W., Cnaan, R.A., Gelles, R.J.: Adolescent risk behaviors and religion: Findings from a national study. Journal of adolescence 30(2), 231-249 (2007)

18. Landor, A., Simons, L.G., Simons, R.L., Brody, G.H., Gibbons, F.X.: The role of religiosity in the relationship between parents, peers, and adolescent risky sexual behavior. Journal of youth and adolescence 40(3), 296-309 (2011)

19. Hust, S.J., Brown, J.D., L’Engle, K.L.: Boys will be boys and girls better be prepared: An analysis of the rare sexual health messages in young adolescents' media. Mass communication \& society 11(1), 3-23 (2008)

20.Johnson, B.T., Scott-Sheldon, L.A.J., Carey, M.P.: Meta-synthesis of health behavior change meta-analyses. American Journal of Public Health 100(11), 2193-2198 (2010)

21. Rosenberger, J.G., Bell, D.L., McBride, K.R., Fortenberry, J.D., Ott, M.A.: Condoms and developmental contexts in younger adolescent boys. Sexually transmitted infections 86(5), 400-403 (2010)

22. Commendador, K.A.: Parental influences on adolescent decision making and contraceptive use. Pediatric Nursing 36(3), 147-158 (2010) 23. DiClemente, R.J., Wingood, G.M., Crosby, R., Cobb, B.K., Harrington, K., Davies, S.L.: Parent-adolescent communication and sexual risk behaviors among african american adolescent females. The Journal of pediatrics 139(3), 407-412 (2001)

24.Krauss, B.J., Miller, K.S.: In: Pequegnat, W., Bell, C.C. (eds.) Parents as HIV/AIDS Educators, pp. 97-120. Springer, New York, NY (2012) 25. DiClemente, R.J., Wingood, G.M., Crosby, R., Sionean, C., Cobb, B.K., Harrington, K., Davies, S., Hook, E.W., Oh, M.K.: Parental monitoring: Association with adolescents' risk behaviors. Pediatrics 107(6), 1363$1368(2001)$ 
26. Stattin, H., Kerr, M.: Parental monitoring: A reinterpretation. Child Development 71(4), 1072-1085 (2000)

27. Dishion, T.J., McMahon, R.J.: Parental monitoring and the prevention of child and adolescent problem behavior: A conceptual and empirical formulation. Clinical child and family psychology review 1(1), 61-75 (1998)

28.Simons, L.G., Sutton, T.E., Simons, R.L., Gibbons, F.X., Murry, V.M.: Mechanisms that link parenting practices to adolescents' risky sexual behavior: A test of six competing theories. Journal of Youth and Adolescence 45(2), 255-270 (2015)

29. Thompson, K., Roemer, A., Leadbeater, B.: Impulsive personality, parental monitoring, and alcohol outcomes from adolescence through young adulthood. Journal of Adolescent Health 57(3), 320-326 (2015)

30.Eaton, N.R., Krueger, R.F., Johnson, W., McGue, M., Iacono, W.G.: Parental monitoring, personality, and delinquency: Further support for a reconceptualization of monitoring. Journal of Research in Personality 43(1), 49-59 (2009)

31. Padilla-Walker, L.M., Nelson, L.J., Madsen, S.D., Barry, C.M.: The role of perceived parental knowledge on emerging adults' risk behaviors. Journal of Youth and Adolescence 37(7), 847-859 (2008)

32. Branstetter, S.A., Furman, W.: Buffering effect of parental monitoring knowledge and parent-adolescent relationships on consequences of adolescent substance use. Journal of Child and Family Studies 22(2), 192198 (2013)

33.Lonczak, H.S., Abbott, R.D., Hawkins, J.D., Kosterman, R., Catalano, R.F.: Effects of the seattle social development project on sexual behavior, pregnancy, birth, and sexually transmitted disease outcomes by age 21 years. Archives of Pediatrics \& Adolescent Medicine 156(5), 438 (2002). doi:10.1001/archpedi.156.5.438 34. Schuster, R.M., Mermelstein, R., Wakschlag, L.: Gender-specific relationships between depressive symptoms, marijuana use, parental 
communication and risky sexual behavior in adolescence. Journal of youth and adolescence 42(8), 1194-1209 (2013)

35. Lansford, J.E., Yu, T., Erath, S.A., Pettit, G.S., Bates, J.E., Dodge, K.A.:

Developmental precursors of number of sexual partners from ages 16 to 22 . Journal of Research on Adolescence 20(3), 651-677 (2010)

36. Ellis, D.A., Podolski, C.-L., Frey, M., Naar-King, S., Wang, B., Moltz, K.: The role of parental monitoring in adolescent health outcomes: Impact on regimen adherence in youth with type 1 diabetes. Journal of Pediatric Psychology 32(8), 907-917 (2007)

37. Frisco, M.L.: Parental involvement and young women's contraceptive use. Journal of Marriage and Family

$$
67(1), 110-121(2005)
$$

38. Blum, R.W.: Young people: not as healthy as they seem. The Lancet 374(9693), 853-854 (2009) 39. Rehm, J., Baliunas, D., Borges, G.L.G., Graham, K., Irving, H., Kehoe, T., Parry, C.D., Patra, J., Popova, S., Poznyak, V., Roerecke, M., Room, R., Samokhvalov, A.V., Taylor, B.: The relation between different dimensions of alcohol consumption and burden of disease: an overview. Addiction 105(5), 817-843 (2010)

40.Blas, E., Kurup, A.S.: Equity, Social Determinants and Public Health Programmes. World Health Organization, Switzerland (2010)

41. Blum, R.W., Nelson-Mmari, K.: The health of young people in a global context. Journal of Adolescent health 35(5), 402-418 (2004)

42. Babor, T.F., Caulkins, J.P., Edwards, G., Fischer, B., Foxcroft, D.R., Humphreys, K., Obot, I.S., Rehm, J., Reuter, P.: Drug Policy and the Public Good. Oxford university press, New York (2010)

43. Fatusi, A.O., Hindin, M.J.: Adolescents and youth in developing countries: Health and development issues in context. Journal of Adolescence 33(4), 499-508 (2010)

44.Hardee, K., Pine, P., Wasson, L.T.: Adolescent and youth reproductive health in the asia and near east region: status issues policies and programs. 
594

595

596

597

598

599

600

601

602

603

604

605

606

607

608

609

610

611

612

613

614

615

616

617

618

619

620

621

622

623

624
(2003)

45. Al-Sadat, N., Misau, A.Y., Zarihah, Z., Maznah, D., Su, T.T.: Adolescent tobacco use and health in southeast asia. Asia Pacific Journal of Public Health 22(3 suppl), 175-180 (2010)

46. Hong, S.A., Peltzer, K.: Early adolescent patterns of alcohol and tobacco use in eight association of south-east asian nations (ASEAN) member states.

Substance Use \& Misuse 54(2), 288-296 (2018)

47. World Health Organization: Substance use in south-east asia: knowledge, attitudes, practices and opportunities for intervention: summary of baseline assessments in thailand, philippines and viet nam (2003)

48.Chamratrithirong, A., Miller, B.A., Byrnes, H.F., Rhucharoenpornpanich, O., Cupp, P.K., Rosati, M.J., Fongkaew, W., Atwood, K.A., Chookhare, W.: Spirituality within the family and the prevention of health risk behavior among adolescents in bangkok, thailand. Social Science \& Medicine 71(10), $1855^{-1863(2010)}$

49.Phuong, T.B., Huong, N.T., Tien, T.Q., Chi, H.K., Dunne, M.P.: Factors associated with health risk behavior among school children in urban vietnam. Global Health Action 6(1), 18876 (2013)

50.Le, H.T., Singhasivanon, P., Kaewkungwal, J., Kaljee, L.M., Charoenkul, C.: Sexual behaviors of alcohol drinkers and non-drinkers among adolescents and young adults in nha trang, vietnam. Southeast Asian journal of tropical medicine and public health 38(1), 152 (2007)

51. Le, T.N., Kato, T.: The role of peer, parent, and culture in risky sexual behavior for cambodian and lao/mien adolescents. Journal of Adolescent Health 38(3), 288-296 (2006)

52. Sychareun, V., Thomsen, S., Faxelid, E.: Concurrent multiple health risk behaviors among adolescents in luangnamtha province, lao PDR. BMC Public Health 11(1) (2011)

53. Chen, P.C., Lee, L.K., Wong, K.C., Kaur, J.: Factors relating to adolescent suicidal behavior: a cross-sectional malaysian school survey. Journal of Adolescent Health 37(4), 337-11 (2005) 
625

626

627

628

629

630

631

632

633

634

635

636

637

638

639

640

641

642

643

644

645

646

647

648

649

650

651

652

653

654

655
54. Omar, K., Hasim, S., Muhammad, N.A., Jaffar, A., Hashim, S.M., Siraj, H.H.: Adolescent pregnancy outcomes and risk factors in malaysia. International Journal of Gynecology \& Obstetrics 111(3), 220-223 (2010)

55. Morrow, M., Barraclough, S.: Tobacco control and gender in southeast asia. part i: Malaysia and the philippines. Health

Promotion International 18(3), 255-264 (2003)

56. Sarmento, D.R., Yehadji, D.: An analysis of global youth tobacco survey for developing a comprehensive national smoking policy in timor-leste. BMC Public Health 16(1) (2015)

57. Siziya, S., Muula, A., Rudatsikira, E.: Prevalence and correlates of current cigarette smoking among adolescents in east timor-leste.

Indian pediatrics 45(12) (2008)

58.Valois, R.F., Oeltmann, J.E., Waller, J., Hussey, J.R.: Relationship between number of sexual intercourse partners and selected health risk behaviors among public high school adolescents. Journal of Adolescent Health 25(5), 328-335 (1999)

59. Storholm, E.D., Ewing, B.A., Holliday, S.B., Stein, B.D., Meredith, L.S., Shadel, W.G., D.Amico, E.J.: Using marijuana, drinking alcohol or a combination of both: the association of marijuana, alcohol and sexual risk behaviour among adolescents. Sexual Health 15(3), 254 (2018)

6o.Bryan, A., Ray, L.A., Cooper, M.L.: Alcohol use and protective sexual behaviors among high-risk adolescents. Journal of Studies on Alcohol and Drugs 68(3), 327-335 (2007)

61. Johnston, L.D., Miech, R.A., O’Malley, P.M., Bachman, J.G., Schulenberg, J.E., Patrick, M.E.: Monitoring the future national survey results on drug use, 1975-2018: Overview, key findings on adolescent drug use. Institute for Social Research (2019)

62. Bryan, A.D., Schmiege, S.J., Magnan, R.E.: Marijuana use and risky sexual behavior among high-risk adolescents: Trajectories, risk factors, and event-level relationships. Developmental Psychology 48(5), 1429-1442 (2012) 
656

657

658

659

660

661

662

663

664

665

666

667

668

669

670

671

672

673

674

675

676

677

678

679

680

681

682

683

684

685

686

63. Borawski, E.A., Ievers-Landis, C.E., Lovegreen, L.D., Trapl, E.S.: Parental monitoring, negotiated unsupervised time, and parental trust: the role of perceived parenting practices in adolescent health risk behaviors. Journal of Adolescent Health 33(2), 60-70 (2003)

64.Champion, H., Foley, K., Durant, R., Hensberry, R., Altman, D., Wolfson, M.: Adolescent sexual victimization, use of alcohol and other substances, and other health risk behaviors. Journal of Adolescent Health 35(4), 321$328(2004)$

65. Kaltiala-Heino, R., Fr”ojd, S., Marttunen, M.: Depression, conduct disorder, smoking and alcohol use as predictors of sexual activity in middle adolescence: a longitudinal study. Health Psychology and Behavioral Medicine 3(1), 25-39 (2015)

66.Long, S.J., Long, J.S., Freese, J.: Regression Models for Categorical Dependent Variables Using Stata. Stata press, The United States of America (2006). Chap. 4

67. Hill, R.C., Griffiths, W.E., Lim, G.C., Lim, M.A.: Principles of Econometrics vol. 5, p. 603. Wiley Hoboken, NJ, The United States of America (2008). Chap. 16

68.Abar, C.C., Jackson, K.M., Colby, S.M., Barnett, N.P.: Parent-child discrepancies in reports of parental monitoring and their relationship to adolescent alcohol-related behaviors. Journal of Youth and Adolescence 44(9), 1688-1701 (2014)

69. Ryan, J., Roman, N.V., Okwany, A.: The effects of parental monitoring and communication on adolescent substance use and risky sexual activity: A systematic review. The Open Family Studies Journal 7(1), 1227 (2015)

70.Ellickson, P.L., McCaffrey, D.F., Ghosh-Dastidar, B., Longshore, D.L.: New inroads in preventing adolescent drug use: Results from a large-scale trial of project ALERT in middle schools. American Journal of Public Health 93(11), 1830-1836 (2003)

71. Kaljee, L., Genberg, B., Minh, T., Tho, L., Thoa, L., Stanton, B.: Alcohol 
687

688

689

690

691

692

693

694

695

696

697

698

699

700

701

702

703

704

705

706

707

708

709

710

711

712

713

714

715

716

717

use and hiv risk behaviors among rural adolescents in khanh hoa province

viet nam. Health education research 20(1), 71-80 (2004)

72. Metrik, J., Kahler, C.W., Reynolds, B., McGeary, J.E., Monti, P.M., Haney, M., de Wit, H., Rohsenow, D.J.: Balanced placebo design with marijuana:

Pharmacological and expectancy effects on impulsivity and risk taking.

Psychopharmacology 223(4), 489-499 (2012)

73. Valera, P., Epperson, M., Daniels, J., Ramaswamy, M., Freudenberg, N.:

Substance use and HIV-risk behaviors among young men involved in the criminal justice system. The American Journal of Drug and Alcohol Abuse $35(1), 43-47$ (2009)

74. World Health Organization: Global Status Report on Alcohol and Health, 2018. World Health Organization, Switzerland (2019)

75. Chongsuvivatwong, V., Phua, K.H., Yap, M.T., Pocock, N.S., Hashim, J.H., Chhem, R., Wilopo, S.A., Lopez, A.D.: Health and health-care systems in southeast asia: diversity and transitions. The Lancet 377(9763), 429-437 (2011)

76. Summerskill, W., Horton, R.: Health in southeast asia. The Lancet 377(9763), 355-356 (2011)

77. Macaulay, J.: Timor leste: Newest and poorest of asian nations. Geography, 40-46 (2003)

78. Rasiah, R., Miao, Z.: Reducing poverty in timor-leste through stimulating growth and structural change. Institutions and Economies, $39-66(2017)$

79. Molnar, A.K.: Timor Leste: Politics, History, and Culture. Routledge, New York (2009)

80.Taylor-Leech, K.: Sustaining language policy and language rights in east timor: where to from here? (2007)

81. Blum, R.W., Beuhring, T., Shew, M.L., Bearinger, L.H., Sieving, R.E., Resnick, M.D.: The effects of race/ethnicity, income, and family structure on adolescent risk behaviors. American journal of public health 90(12), 1879 (2000) 


\section{Tables}

719

720

721

722

723

724

725

Table I Age and gender of respondents by countries

\begin{tabular}{llllll}
\hline Country & Age $^{*}$ & \multicolumn{5}{c}{ Gender } & Freq. \\
& Mean & S.D. & Mean & S.D. & \\
\hline Brunei & 4.52 & 1.24 & 0.53 & 0.50 & 2599 \\
Indonesia & 3.77 & 0.89 & 0.52 & 0.50 & 3116 \\
Laos & 5.31 & 0.91 & 0.54 & 0.50 & 3683 \\
Malaysia & 4.72 & 1.18 & 0.50 & 0.50 & 25507 \\
Myanmar & 4.27 & 1.26 & 0.50 & 0.50 & 2806 \\
The & 4.51 & 1.20 & 0.56 & 0.50 & 5290 \\
Philippines & & & & & \\
Thailand & 3.59 & 1.06 & 0.50 & 0.50 & 2767 \\
Timor-Leste & 4.94 & 1.39 & 0.51 & 0.50 & 3704 \\
Vietnam & 5.19 & 0.87 & 0.53 & 0.50 & 3331 \\
Total & 4.64 & 1.22 & 0.51 & 0.50 & 52803 \\
\hline Note: ${ }^{*}$ Number 3, 4, and 5 represent the age of 13, 14, and 15, respectively.
\end{tabular}

Note: *Number 3, 4, and 5 represent the age of 13, 14, and 15, respectively.

Table 2 Summary of key variables $(n=52,803)$

\begin{tabular}{|c|c|c|c|c|c|}
\hline Variables & Note & Mean & S.D. & Min. & Max. \\
\hline$\overline{\text { Age }}$ & $\begin{array}{l}\text { Groups } 1-6 \text { respectively include participants aged } \\
13-16 \text { and } 18 \text { years }\end{array}$ & 4.635 & 1.222 & 1 & $\overline{6}$ \\
\hline Gender & Girl $($ Value $=1)$ & 0.514 & 0.499 & 0 & 1 \\
\hline Parental monitoring & Perceived parental monitoring & 0.216 & 0.412 & 0 & 1 \\
\hline Alcohol & At least once consumed alcohol in the past 30 days & 0.136 & 0.343 & 0 & 1 \\
\hline Substance & At least once used substance during life & 0.139 & 0.346 & 0 & 1 \\
\hline Smoke & At least once consumed tobacco in the past 30 days & 0.112 & 0.315 & 0 & 1 \\
\hline Had sex & Ever had sex & 0.069 & 0.254 & 0 & 1 \\
\hline Condomless & Did not use condom during the last sex & 0.019 & 0.139 & 0 & 1 \\
\hline Partners & At least two sexual partners & 0.187 & 0.390 & 0 & 1 \\
\hline
\end{tabular}

Note: $\quad$ Myanmar and the Philippines do not provide information on adolescents' sexual behavior.

Additionally, the Philippines does not have information on substance

use.

Table 3 Association between perceived parental monitoring and adolescents' health risk behaviors 


\begin{tabular}{|c|c|c|c|c|c|c|c|c|}
\hline & \multicolumn{2}{|c|}{$\begin{array}{l}\text { Perceived } \\
\text { Monitoring }\end{array}$} & \multicolumn{3}{|c|}{$\begin{array}{c}\text { Univariate } \\
\text { Analysis }\end{array}$} & \multicolumn{3}{|c|}{$\begin{array}{c}\text { Multivariate } \\
\text { Analysis }\end{array}$} \\
\hline & Less & More & OR & $(95 \% \mathrm{Cl})$ & $p$ value & OR & $(95 \% \mathrm{Cl})$ & $p$ value \\
\hline & $\%$ & $\%$ & & & & & & \\
\hline \multicolumn{9}{|l|}{ Sexual behavior } \\
\hline Ever had sex & 7.62 & 4.45 & 0.56 & $(0.51-0.62)$ & 0.000 & 0.72 & $(0.65-0.79)$ & 0.000 \\
\hline Condomless & 2.24 & 1.04 & 0.45 & $(0.37-0.55)$ & 0.000 & 0.55 & $(0.45-0.67)$ & 0.000 \\
\hline Partners & 17.66 & 22.74 & 1.37 & $(1.30-1.44)$ & 0.000 & 0.75 & $(0.65-0.86)$ & 0.000 \\
\hline \multicolumn{9}{|l|}{ Substance use } \\
\hline Alcohol & 15.12 & 8.29 & 0.50 & $(0.47-0.54)$ & 0.000 & 0.62 & $(0.58-0.67)$ & 0.000 \\
\hline Substance & 14.97 & 10.25 & 0.64 & $(0.60-0.69)$ & 0.000 & 0.72 & $(0.63-0.83)$ & 0.000 \\
\hline Smoking & 12.39 & 6.99 & 0.53 & $(0.49-0.57)$ & 0.000 & 0.61 & $(0.56-0.66)$ & 0.000 \\
\hline
\end{tabular}

Note: $\quad$ Multivariate analysis is adjusted for age, gender, and country.

733

Table 4 Health risk behaviors in girls

\begin{tabular}{|c|c|c|c|c|c|c|c|c|}
\hline & Gen & & & $\begin{array}{c}\text { Univariate } \\
\text { Analysis }\end{array}$ & & & $\begin{array}{c}\text { Multivariate } \\
\text { Analysis }\end{array}$ & \\
\hline & $\mathrm{M}$ & $\mathrm{F}$ & OR & $(95 \% \mathrm{Cl})$ & $p$ value & OR & $(95 \% \mathrm{Cl})$ & $p$ value \\
\hline & $\%$ & $\%$ & & & & & & \\
\hline Sexual behavior & & & & & & & & \\
\hline Ever had sex & 8.53 & 5.43 & 0.61 & $(0.57-0.65)$ & 0.000 & 0.62 & $(0.57-0.66)$ & 0.000 \\
\hline Condomless & 2.56 & 1.43 & 0.55 & $(0.23-0.51)$ & 0.000 & 0.57 & $(0.50-0.65)$ & 0.000 \\
\hline Partners & 19.49 & 18.08 & 0.91 & $(0.87-0.95)$ & 0.000 & 0.36 & $(0.32-0.40)$ & 0.000 \\
\hline Substance use & & & & & & & & \\
\hline Alcohol & 17.20 & 10.28 & 0.55 & $(0.52-0.58)$ & 0.000 & 0.51 & $(0.49-0.54)$ & 0.000 \\
\hline Substance & 11.19 & 11.72 & 0.93 & $(0.89-0.98)$ & 0.014 & 0.46 & $(0.42-0.51)$ & 0.000 \\
\hline Smoking & 19.18 & 3.12 & 0.13 & $(0.08-0.12)$ & 0.000 & 0.12 & $(0.11-0.13)$ & 0.000 \\
\hline
\end{tabular}

Note: $\quad$ Multivariate analysis is adjusted for age, gender, and country.

Table 5 Health risk behaviors of different ages

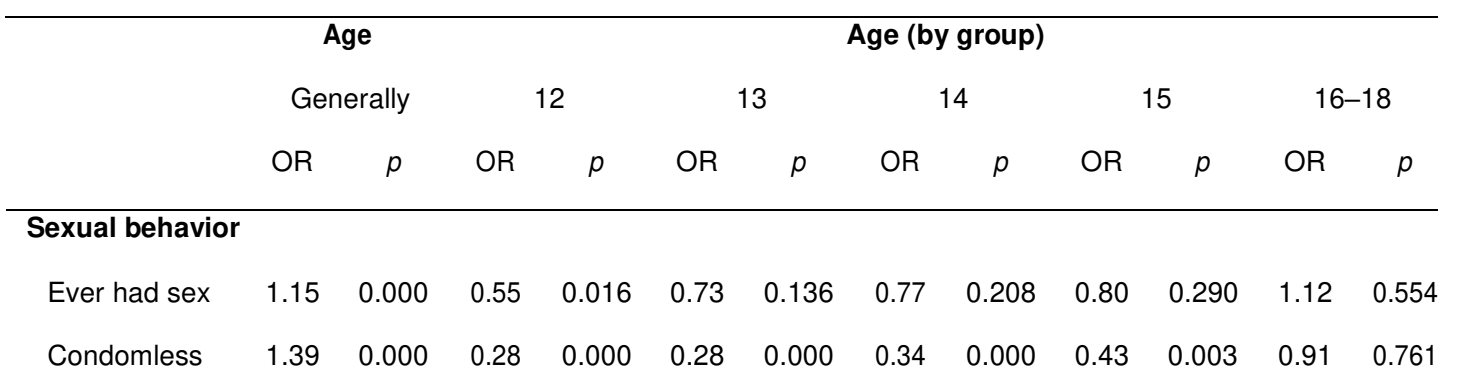




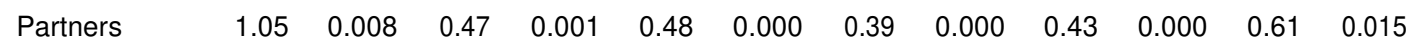

\section{Substance use}

$\begin{array}{lllllllllllll}\text { Alcohol } & 1.25 & 0.000 & 0.32 & 0.000 & 0.35 & 0.000 & 0.44 & 0.000 & 0.53 & 0.000 & 0.77 & 0.094 \\ \text { Substance } & 0.91 & 0.000 & 0.33 & 0.000 & 0.40 & 0.000 & 0.41 & 0.000 & 0.35 & 0.000 & 0.34 & 0.000 \\ \text { Smoke } & 1.33 & 0.000 & 0.25 & 0.000 & 0.33 & 0.000 & 0.45 & 0.000 & 0.61 & 0.000 & 0.87 & 0.000\end{array}$

Note: Multivariate analysis is used; 11 years is the base age.

Table 6 Association between using substance and sexual risk behaviors

\begin{tabular}{lccccccccc}
\hline \multicolumn{3}{c}{ Ever had sex } & \multicolumn{3}{c}{ Condomless } & & Partners \\
& OR & $(95 \% \mathrm{Cl})$ & $p$ value & OR & $(95 \% \mathrm{Cl})$ & $p$ value & OR & $(95 \% \mathrm{Cl})$ & $p$ value \\
\hline Demographic & & & & & & & & & \\
Age & 1.14 & $(1.10-1.17)$ & 0.000 & 1.33 & $(1.25-1.41)$ & 0.000 & 1.04 & $(1.00-1.09)$ & 0.043 \\
Gender & 0.76 & $(0.71-0.82)$ & 0.000 & 0.87 & $(0.76-1.01)$ & 0.074 & 0.53 & $(0.47-0.59)$ & 0.000 \\
Substance & & & & & & & & & \\
Alcohol & 1.49 & $(1.35-1,63)$ & 0.000 & 1.95 & $(1.67-2.28)$ & 0.000 & 2.30 & $(2.04-2.59)$ & 0.000 \\
Substance & 3.10 & $(2.76-3.48)$ & 0.000 & 2.63 & $(2.18-3.38)$ & 0.000 & 7.86 & $(6.90-8.96)$ & 0.000 \\
Smoking & 1.85 & $(1.68-2.03)$ & 0.000 & 2.84 & $(2.43-3.32)$ & 0.000 & 2.11 & $(1.86-2.39)$ & 0.000 \\
\hline
\end{tabular}

Table 7 Difference of sexual risky behavior in Southeast Asia

\begin{tabular}{|c|c|c|c|c|c|c|c|c|c|}
\hline & \multicolumn{3}{|c|}{ Ever had sex } & \multicolumn{3}{|c|}{ Condomless } & \multicolumn{3}{|c|}{ Partners } \\
\hline & OR & $(95 \% \mathrm{Cl})$ & $p$ value & OR & $(95 \% \mathrm{Cl})$ & $p$ value & OR & $(95 \% \mathrm{Cl})$ & $p$ value \\
\hline Brunei & 2.21 & $(1.82-2.68)$ & 0.000 & 1.46 & $(0.99-2.15)$ & 0.052 & 1.76 & $(1.28-2.43)$ & 0.000 \\
\hline Indonesia & 0.11 & $(0.07-0.29)$ & 0.000 & 4.74 & $(3.42-6.57)$ & 0.000 & 0.98 & $(0.68-1.40)$ & 0.934 \\
\hline Laos & 2.27 & $(1.90-2.71)$ & 0.000 & 1.30 & $(0.92-1.84)$ & 0.123 & 2.02 & $(1.51-2.70)$ & 0.000 \\
\hline Malaysia & 1.41 & $(1.21-1.65)$ & 0.000 & 1.03 & $(0.77-1.37)$ & 0.829 & 1.21 & $(0.94-1.56)$ & 0.123 \\
\hline Myanmar & 1.00 & & & 1.00 & & & 1.00 & & \\
\hline The & 1.00 & & & 1.00 & & & 1.00 & & \\
\hline \multicolumn{10}{|l|}{ Philippines } \\
\hline Thailand & 1.16 & $(0.92-1.46)$ & 0.185 & 4.61 & $(3.29-6.45)$ & 0.000 & 6.58 & $(4.99-8.66)$ & 0.000 \\
\hline Timor-Leste & 3.86 & $(3.26-4.58)$ & 0.000 & 3.28 & $(2.42-4.44)$ & 0.000 & 7.02 & $(5.42-9.09)$ & 0.000 \\
\hline
\end{tabular}




\begin{tabular}{|c|c|c|c|c|c|c|c|c|c|}
\hline & \multicolumn{3}{|c|}{ Alcohol } & \multicolumn{3}{|c|}{ Substance } & \multicolumn{3}{|c|}{ Smoking } \\
\hline & OR & $(95 \% \mathrm{Cl})$ & $p$ value & OR & $(95 \% \mathrm{Cl})$ & $p$ value & OR & $(95 \% \mathrm{Cl})$ & $p$ value \\
\hline Brunei & 0.19 & $(0.15-0.22)$ & 0.000 & 1.94 & $(1.38-2.72)$ & 0.000 & 3.03 & $(2.45-3.73)$ & 0.000 \\
\hline Indonesia & 0.24 & $(0.20-0.28)$ & 0.000 & 0.34 & $(0.20-0.57)$ & 0.000 & 5.02 & $(4.11-6.13)$ & 0.000 \\
\hline Laos & 1.08 & $(0.97-1.20)$ & 0.158 & 1.39 & $(0.99-1.95)$ & 0.053 & 1.02 & $(0.81-1.27)$ & 0.850 \\
\hline Malaysia & 0.24 & $(0.20-0.28)$ & 0.000 & 1.99 & $(1.52-2.60)$ & 0.000 & 2.88 & $(2.43-3.41)$ & 0.000 \\
\hline Myanmar & 0.17 & $(0.14-0.21)$ & 0.000 & 0.24 & $(0.13-0.45)$ & 0.000 & 1.73 & $(1.37-2.18)$ & 0.000 \\
\hline The & 0.92 & $(0.83-1.02)$ & 0.128 & 1.00 & & & 3.78 & $(3.14-4.55)$ & 0.000 \\
\hline \multicolumn{10}{|l|}{ Philippines } \\
\hline Thailand & 1.23 & $(1.08-1.39)$ & 0.001 & 3.54 & $(2.60-4.82)$ & 0.000 & 4.24 & $(3.45-5.22)$ & 0.000 \\
\hline Timor-Leste & 0.91 & $(0.81-1.02)$ & 0.109 & 13.09 & $(9.94-17.24)$ & 0.000 & 7.32 & $(6.10-8.80)$ & 0.000 \\
\hline
\end{tabular}

Note: Multivariate regression with Model (1); the dependent variable is substance use.

Table 9 Policies and interventions of alcohol in Southeast Asia

\begin{tabular}{|c|c|c|c|c|c|c|c|c|c|}
\hline Index & Indo & Thai & Timo & Brun & Lao & Mala & Myan & $\begin{array}{l}\text { The } \\
\text { Phili }\end{array}$ & $\overline{\text { Viet }}$ \\
\hline$\overline{\text { Alcohol/GDP (\%) }}$ & 0.8 & 8.3 & 2.1 & 0.4 & 10.4 & 0.9 & 4.8 & 6.6 & 8.3 \\
\hline Written national policy & Yes & Yes & No & - & Yes & Yes & No & Yes & Yes \\
\hline National Action Plan & No & Yes & - & - & No & Yes & Yes & Yes & Yes \\
\hline Excise tax & Yes & Yes & Yes & - & Yes & Yes & Yes & Yes & Yes \\
\hline National legal minimum age for on premise & 20 & 20 & No & - & 18 & 21 & 18 & 18 & 18 \\
\hline Restriction for on premise sales of alcoholic beverage & Yes & Yes & No & - & Yes & Yes & Yes & Yes & No \\
\hline National maximum legal $\mathrm{BAC}^{*}$ when driving a vehicle & No & 0.05 & 0.05 & - & 0.08 & 0.08 & 0.08 & 0.05 & 0.05 \\
\hline Legally binding regulations on alcohol advertising & Yes & Yes & No & - & Yes & Yes & Yes & No & Yes \\
\hline Legally binding regulations on alcohol sponsorship & Yes & Yes & No & - & Yes & No & Yes & No & Yes \\
\hline Legally require health warning labels on advertisements & No & No & No & - & Yes & No & No & Yes & No \\
\hline National government support for community action & Yes & Yes & Yes & - & No & Yes & No & Yes & Yes \\
\hline National monitoring systems & No & Yes & No & - & No & Yes & Yes & No & Yes \\
\hline
\end{tabular}


Figures

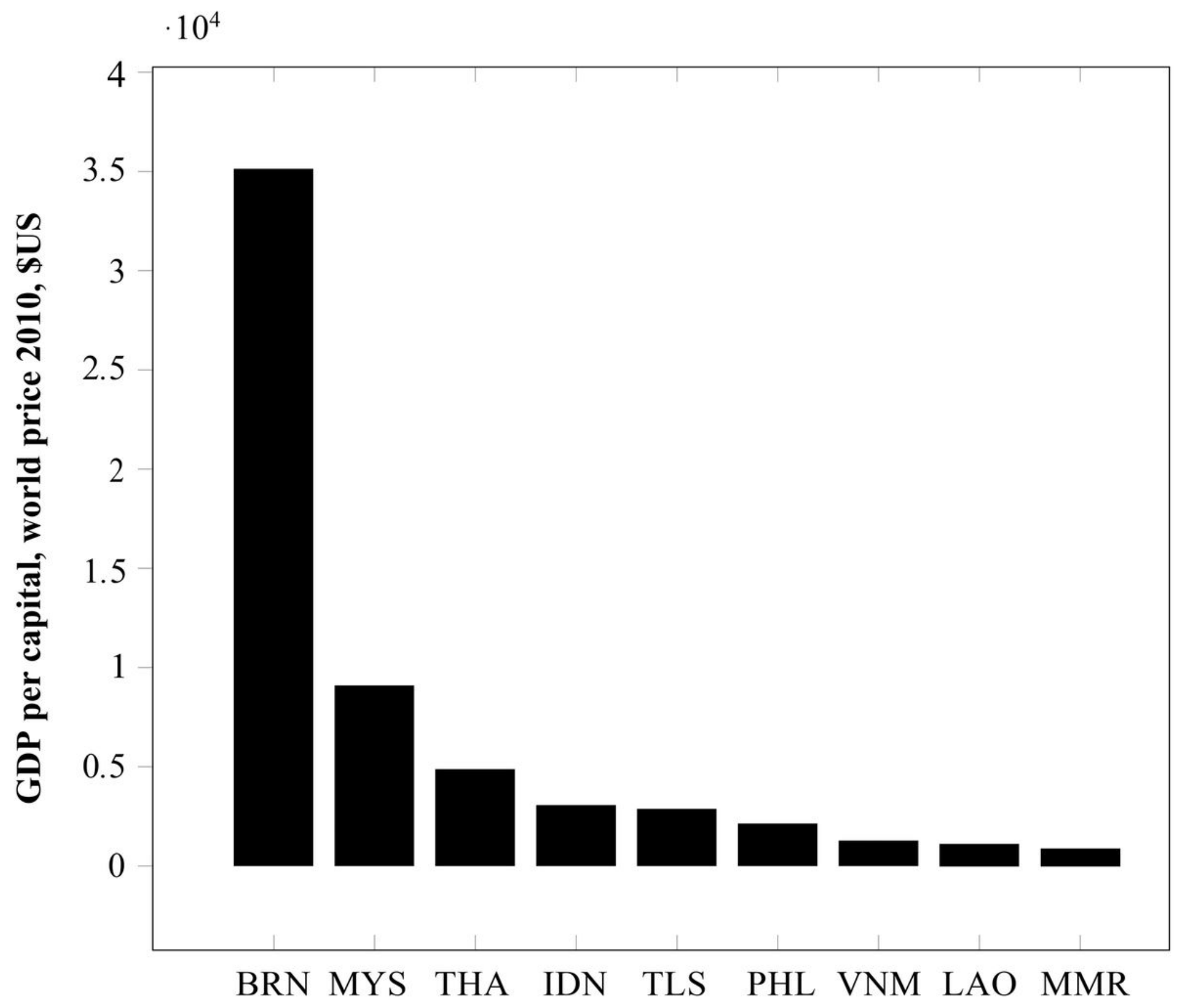

Figure 1

GDP per capital of each country when the survey was conducted, \$US. 